The other points in which I differ from Mr. Venn have been mentioned in my former letters (see NATURE, vol. xxiii. p. 578 , and vol. xxiv. p. 5), and need not be here repeated. Mr. Venn however labours under a seriou: misapprehension if he thinks that I attach any importance to the distinguishing features of my method as mere barren conceptions. Their real importance lies in the use which I have made of them, and this use cannot be fairly appreciated without examination of my published solutions in the Proceedings of the London Mathematical Society, in the Educational Times, and in the Philosophical Magazine. I must protest against that spirit of criticism which would offer two or three chipped bricks as a fair specimen of a house, ard would depreciate the labours and damp the zeal of all scientific workers by unduly emphasising the undeniable fact that all logical and mathematical methods are, after all, mere combinations, developments, or extensions of a few simple truths which are the common property of all mankind. Even Boole's "actual originality," Mr. Venn tells us, though I think he means priority, "was by no means so complete as is comm only supposed and asserted" (see Mr. Venn's Introduction, p. 28). According to this method of criticisn we might ascribe the invention of the steam-engine to the person (unfortunately unknown) who first discovered the important principle of a revolving wheel, and turned it to practical account by making a wheel-barrow.

In conclusion I must thank Mr. Venn for the compliment which he kindly pays me on p. 372 of his work, but I think it would read better without the parenthesis, "as he assures us is the case." The "assures" is a little too strong for the simple statements which I made, and which it never occurred to me that any one would dream of doubting. The compliment would also please me more if it did not so completely ignore the earliest, the most difficult, and the most important of my papers in the Proceedings of the Mathematical Society, namely, that which treats of the limits of multiple integralis. This part of my method (which gave rise to all the succeeding developments) resembles nothing, so far as I know, that has preceded it; and if Mr. Venn had found time to read it, the objectionable parenthesis which I have quoted would scarcely have presented itself to his mind as in any way called for.

Boulogne, May 25

\section{Resonance of the Mouth-Cavity}

SinCe communicating to Mr. Sedley Taylor my recent ob. servations on the capabilities of the mouth as a resouator, and forwarded to you, with my permission, for publication in NATURE, I have made the following experiments with perfect success, and believing that they will be interesting to your acoustical readers I send a list of them to you, and hope you will be able to find a place for its insertion in your next issue :-

Experiment 1.-While one of the overtones of a loud prime was resounding in my mouth another person heard it distinctly, upon the ear of the latter being held near the source of resonance.

Experimen: II.-While a cart-any other noisy vehicle will do as well-was going along the street, I readily tested the composite nature of the noise by the resonant capabilities of my mouth.

Experimen! III.-I turned the water-tap on into a basin (the water was running with a good force), and from the noise make by the falling liquid I was able to get different sounds quite easily.

In both these latter experiments I observed, while opening and closing my mouth, that the pitch rose and fell as when one slides a finger up and down a vibrating fiddle-string.

Experiment $I V$. - I held down in the treble part of a harmonium-with an 8-feet stop out-several consecutive keys together, and while the notes were sounding which composed the horrible discord, I was able to single out any of them separately by the sympathetic resonance of my mouth.

This experiment can be done equally well at the organ.

Experiment V.-I held down four or five of the low keys of the organ with the 8 -feet trumpet drawn, and the beats of the overtones resounded very prominently, so that by taking two contiguous ones at a time the result was like the voix celleste stop.

Experiment V1. - I tried severd notes in the $c-c$ octave of the clarinet organ stop, and heard the rezular order of partial tones by resonance, but the even ones were weak and odd ones very strong.

Experiment VII.-I held down $c^{\prime}$ and $g^{\prime}$ on the harmsnium, and heard the first coincident partials beat distinctly-due to equal temperament.

Experiment VIII.-The first five partial tones of an average bass voice were studied. The notes chosen for ob.servation were b, $f, g, a b, b$. To each note the vowels $A$ as in hay, $A$ as in $a h, E$ as in $m e, I$ as in high, $O$ as in oh, $U$ as in you, were sung. It was found that not only did the different vowels give different qualities, but that the same vowel had a different quality for almost every one of the five notes sung. The $E$ as in $m e$ and $U$ as in you had generally weak low overtones. The $I$ as in high, on the contrary, gave them out well.

It will perhaps be as well to say, for the benefit of those who may not have tried to get a sympathetic resonance of the mouth, that success is likely to be sooner obtained by first practising the mouth in going from the $o u$ to the $a h$ shape, and from the $o u$ to to the $e$ shape.

It is also recommended that the ears be stopped by the fingers when doing these experiments, in order to lessen the possibility of mistaking the direct sound for resonance.

\section{5, West Park Terrace, Scarborough, June I}

JOHN NAyLOR

\section{"How to Prevent Drowning"}

I FEAR that if persons who cannot swim place reliance on the advice given by Mr. MacCormac in your impression of June 2 (vol. xxiv.pp. 62, IOI) they will hardly succeed in saving their lives should they happen to fall into deep water. It is an error to say that the "human frame, bulk for bulk, is lighter than water," for unless that frame be covered with fat beyond the average, it has a greater specific gravity than water. And after all, a tolerably fat body is lighter, bulk for bulk, than wates only by virtue of the air in its lungs, and should that air be expelled by the frantic screams of the immersed person, he will soon find, if unable to swim, that the notion of his frame being specifically lighter than the water is a myth. The dead body even of a tolerably fat person being destitute of air in the lungs, sinks at once to the bottom in salt as in fresh water. The average human being, were he to permit his body to sink as far as it will, would soon find himself at the bottom of the sea or river. Besides, even in the case of a person fat enough to be lighter, bulk for bulk, than water, it is necessary that he should assume a certain position in order that he may succeed in keep. ing his nose and mouth above the water, and unless he learn how to do this in the water itself I doubt if instruction on dry land would ever enable him to float. We all know the story of the Hibernian who, having narrowly escaped drowning, vowed he would never enter the water again until he had learnt to swim, but we are not told if he ever qualified himself for going into the water again. To try and persuade people that by attending to certain rules they may get into deep water without the risk of drowning is to create a false cunfidence which will rather increase than diminish the number of deaths by drowning. Imagine a terrified person just plunged for the first time into deep water trying to recall all the directions he has read about shutting his lips, swallowing his breath, permitting his body to sink until it shail displace as much water as equals the body's weight, treading the water, and so on. Why he would require, in the midst of his a rony of fear, to possess as many contradictory qualitie of mind as Macbeth says no man can have. I venture to assert that no one was ever saved from drowning by following such directions as your correspondents here give. It should be stated in the plainest manner that there is no safety for a person in deep water but in a knowledge of swimming. Swimming should be taught to every boy and girl as a necessary branch of education. It has these advantages over much that is taught in schools, that it is a useful, a delightful, and a healthful accomplishment.

52, Montagu Square, W., June 3

\section{Dust-winds at Hankow}

DURING the spring of 1878 my attention was directed to the dust-winds which are not of unfrequent occurrence along the valley of the Yang-tse in the warm and dry seasons of the year. These dust-winds, as I observed them at Hankow, had sometimes the appearance of a dense mist; whilst at other times the air seemed to be penetrated by a fine haze; and in all cases a fine and almost impalpable dust was deposited 